\title{
CUSTO DO GADO BOVINO RASTREADO DA FAZENDA CACHOEIRA E OUTRAS EM TANGARÁ DA SERRA: USO DO CUSTEIO VARIÁVEL
}

\author{
Ederson Junio Pelissari ${ }^{1}$ \\ Laércio Juarez Melz ${ }^{2}$ \\ Cleiton Franco ${ }^{3}$ \\ Priscila Meliane Leite dos Anjos ${ }^{4}$
}

\begin{abstract}
RESUMO
A pesquisa teve como objetivo apresentar os custos de produção de gado rastreado envolvidos nas etapas que os animais passam na propriedade rural. Esta análise foi realizada no município de Tangará da Serra com 22 propriedades rurais que pertencem à lista trace da European Comission. Foram coletados e analisados dados de 17 propriedades rurais, através de questionário. Foram questionados: a forma de manejo dos animais, as vantagens e desvantagens no processo de rastreabilidade e se o custo com a rastreabilidade é compensador para a atividade. Adicionalmente, foi realizado levantamento junto a uma propriedade sobre os custos fixos e variáveis para produção de um lote com 3000 cabeças de gado. Concluiu-se que o custo do gado rastreado é R\$ 5,38 maior, por cabeça, que o do gado não rastreado, representando gasto com cadastro do animal e renovação semestral do certificado ERAS da propriedade. A principal vantagem percebida pelos produtores é o bônus que recebem do frigorífico da venda de $\mathrm{R} \$ 3,00$ por arroba. Os cálculos confirmaram que, considerando, no mínimo $\mathrm{R} \$ 45,00$ por animal de 15 arrobas, lucro bruto gerado foi de $\mathrm{R} \$ 39,62$ por animal rastreado vendido. Entre as desvantagens apontadas pelos produtores foi o controle mais rígido para o gado rastreado.
\end{abstract}

Palavras-chave: Rastreabilidade. Contabilidade de Custos. Bovinocultura de corte.

\section{INTRODUÇÃO}

O rebanho bovino brasileiro é o maior rebanho comercial do mundo, superando o indiano e o chinês. É composto por cerca de $80 \%$ de animais de raças zebuínas (Bosindicus) e de 20\% de raças taurinas (Bostaurus) (ABIEC, 2011). A bovinocultura de corte representa a maior fatia do agronegócio brasileiro, gerando faturamento de mais de $\mathrm{R} \$ 50$ bilhões/ano e oferecendo cerca de 7,5 milhões de empregos (ABIEC, 2011).

O consumo de carne bovina no Brasil hoje per capita é de $36,5 \mathrm{~kg} / \mathrm{ano}$ abaixo dos EUA 45,6 kg/ano mais ainda acima de países da União Européia (UE). "Além de sermos o maior exportador de carne do mundo" (MARION, 2007a, p.15).

\footnotetext{
${ }^{1}$ Contador formado pela UNEMAT, e-mail: edersonpelissari@ hotmail.com.

${ }^{2}$ Mestre em Engenharia de Produção (UFSCar), Professor do curso de Ciências Contábeis da UNEMAT

- Campus de Tangará da Serra, e-mail: laercio@unemat.br

${ }^{3}$ Mestre em Economia (UFMT), Professor do curso de Ciências Contábeis da UNEMAT - Campus de Tangará da Serra.

${ }^{4}$ Contadora, Professora do curso de Ciências Contábeis da UNEMAT - Campus de Tangará da Serra.

Volume 2, Número $3 \quad$ Revista UNEMAT de Contabilidade

Jan./Jun. 2013

ISSN: 2316-8072
} 
Para Marion (2007a, p.15) "a eficiência e o porte da pecuária exigem novos mecanismos contábeis e de controle, em função do uso cada vez mais intenso de insumos, proporcionando ao refinamento tecnológico da atividade". A atividade pecuária no Mato Grosso é de grande relevância por ser o maior estado produtor e exportador de carne bovina do país, atualmente é o que demonstra o instituto Brasileiro de Geografia e Estatística, (IBGE, 2011). A produção de carne bovina no Brasil está dividida em todo o território nacional onde $39 \%$ concentra-se na região centro oeste do país, destacando-se na economia do gerada no país (IBGE, 2011).

O rebanho bovino cresceu, no Brasil, de 169.875.524 para 205.260.154 milhões de cabeças, um aumento de 20,9\% entre os anos 2000 e 2010 (IBGE, 2011). As exportações brasileiras de carne bovina cresceram 10\% entre 2000 e 2010 é o que revela o Ministério do Desenvolvimento, Indústria e Comércio Exterior (MDIC, 2011).

Devido ao aumento do consumo europeu de carnes, a atividade pecuária sofreu algumas adequações em relação às normas sanitárias, bem como a elevação da qualidade da carne consumida, obrigando as empresas a ampliarem suas instalações e ampliarem a sua infra-estrutura de produção e melhoramento genético do rebanho (CNA, 2011).

A pesquisa realizada é de suma importância, pois, Mato Grosso é um grande produtor de gado bovino rastreado. Observa-se que existe uma quantidade generosa de terras e pouca produção. Sabendo que o produtor brasileiro é conhecido como sendo um dos maiores produtores de grãos e carne do mundo, os produtores rurais usam de suas práticas e buscam sempre estarem aperfeiçoando suas práticas e formas de produção pecuária, mas onde se tem uma margem apertada de lucros a eficácia e o controle dos custos de produção devem ser conhecidos para serem melhorados buscando assim uma melhor gestão da empresa rural é o que apresenta o Instituto de Defesa Agropecuário de Mato Grosso (INDEA, 2011).

Na região de Tangará da Serra é grande a procura por animais rastreados para abate, mas devido a uma exigência muito elevada por parte do Sistema Brasileiro de Identificação e Certificação de Origem Bovina e Bubalina (SISBOV), e do Estabelecimento Rural Aprovado SISBOV, (ERAS) - a oferta é muito restrita, onde no município de Tangará da Serra-MT existem 22 (Vinte e Duas) propriedades auditadas e 
Custo do gado bovino rastreado da fazenda cachoeira e outras em Tangará da Serra: uso do custeio variável

Ederson Junio Pelissari, Laércio Juarez Melz, Cleiton Franco, Priscila Meliane Leite dos Anjos

aptas a exportar carne para a UE (União Européia) com atualmente 170.000 (mil) cabeças de gado rastreado (INDEA, 2011).

Não foram encontrados trabalhos sobre custos de rastreabilidade de bovinos em Tangará da Serra. Devido à grande importância de Mato Grosso no cenário nacional e mundial de carne bovina e a grande importância de Tangará da Serra no cenário matogrossense, aliada à necessidade de rastreamento para habilitar os frigoríficos à exportarem para UE, justifica-se a pesquisa.

O Problema da pesquisa foi definido como: $\mathrm{O}$ custo de manter a rastreabilidade de bovinos de corte é vantajoso para as empresas rurais de Tangará da Serra, a partir da aplicação do custeio variável para identificar os custos?A hipótese testada foi que o custo de manutenção de rastreabilidade de bovinos de corte para as empresas rurais de Tangará da Serra-MT é vantajoso, quando aplicados os conceitos do custeio variável.

O objetivo geral foi verificar se o custo de manter a rastreabilidade de bovinos de corte é vantajoso para as empresas rurais de Tangará da Serra, a partir da aplicação do custeio variável para identificar os custos.

Objetivos Específicos foram: a) Caracterizar os produtores de gado rastreado de Tangará da Serra; b) Descrever o processo de produção para o gado rastreado; c) Identificar os custos envolvidos no processo de produção de gado rastreado em Tangará da Serra; d) Verificar as vantagens e desvantagens de criar gado rastreado; e) Observar se a prática da rastreabilidade agrega valor ao gado que se aplica essa modalidade.

\section{REFERENCIAL TEÓRICO}

\subsection{Conceitos relacionados com custos de produção}

Para melhor compreender os custos identificados na pesquisa é necessário estabelecer os conceitos norteadores. Estes conceitos diferenciam gastos, custos, despesas, desembolsos e perdas.

O gasto é o momento em que a empresa reconhece que deverá desembolsar certa quantia para obter os produtos, mercadorias ou serviços (MEGLIORINI, 2007), é importante ressaltar que existe diferença entre o saber popular e o científico.

Padoveze (2003, p.17) afirma que: 
Gastos são todas as ocorrências de pagamentos ou de recebimentos de ativos, custos ou despesas. Significam receber os serviços e os produtos para consumo em todo o processo operacional, bem como os pagamentos efetuados e os recebimentos de ativos. Como se pode verificar, gastos são ocorrências de grande abrangência e generalização. Gasto também é sinônimo de dispêndio, o ato de despender.

Perez Junior, Oliveira e Costa (2003, p.16) relatam que: “é importante não confundir gastos com desembolsos. Freqüentemente se ouve pessoas dizerem: "gastei muito dinheiro." Na realidade o dinheiro não é gasto, ele é desembolsado".

$\mathrm{Na}$ atividade pecuária é importante o produtor conhecer e saber onde acontece maiores desembolsos dentro da sua atividade, buscando sempre controlar e saber onde foi gasto o valor necessário para sua atividade, e não confundindo gasto com desembolso (PEREZ JUNIOR; OLIVEIRA; COSTA, 2003, p.16)

Crepaldi (2005, p. 97) afirma que:

Gastos são sacrifícios que a entidade arca para obtenção de um bem ou serviço, representando por entrega ou promessa de entrega de ativos (normalmente dinheiro). O gasto se concretiza quando os serviços ou bens adquiridos são prestados ou passam a ser propriedade da empresa rural.

Toda empresa rural sempre busca fazer sacrifícios para melhorar seus ganhos e assim ter um melhor desempenho em sua atividade. Normalmente tem se a impressão que ao realizar um gasto parece ser desnecessário, ou não realizar pode ser um fracasso na empresa por isso sempre é necessário realizar um bom controle financeiro de seus gastos a serem realizados (CREPALDI, 2005).

De acordo com Perez Junior, Oliveira e Costa (2003, p.15) “desembolsos: saídas de dinheiro do caixa ou do banco. Os desembolsos ocorrem devido ao pagamento de uma compra efetuada a vista ou de uma obrigação assumida anteriormente".

Os desembolsos independem de serem somente do período, podem ser também de provisões de período anterior, podem ser também de um empréstimo bancário ou de pagamento de funcionários, sendo também feitos na compra de matéria prima a vista (PEREZ JUNIOR; OLIVEIRA; COSTA, 2003).

Para Martins (2003, p.25) "desembolso significa o pagamento resultante da aquisição do bem ou serviço. Pode ocorrer antes, durante, ou após a entrada da utilidade comprada, portanto defasada ou não no momento do gasto". 
Custo do gado bovino rastreado da fazenda cachoeira e outras em Tangará da Serra: uso do custeio variável

Ederson Junio Pelissari, Laércio Juarez Melz, Cleiton Franco, Priscila Meliane Leite dos Anjos

O conceito de custo apresenta variações quando tratado na contabilidade e em outras ciências, como economia, por exemplo(SCRAMIN ; BATALHA, 2007).

Padoveze (2003, p.17) afirma que:

São os gastos, que não são investimentos, necessários para fabricar os produtos da empresa. São os gastos, efetuados pela empresa, que farão nascer os seus produtos. Portanto, podemos dizer que os custos são os gastos relacionados aos produtos, posteriormente ativados quando os produtos, objeto desses gastos, forem gerados. De um modo geral, são os gastos ligados à área industrial da empresa.

Os custos podem ser identificados no processo de produção da seguinte forma: insumos ou materiais, mão-de-obra direta e indireta, manutenção de máquinas e equipamentos, depreciação de máquinas e equipamentos, energia elétrica, água, serviços de apoio a produção, manutenção, refeitório, ambulatório médico (PADOVEZE 2003, p.17)

Perez Junior, Oliveira e Costa (2003,p.16) relatam que: gastos relativos aos bens e serviços (recursos) consumidos na produção de outros bens e serviços. Observe que não existem despesas de produção, pois todos os gastos incorridos no processo produtivos são classificados como custo.

Para Perez Junior, Oliveira e Costa (2003,p.16) :

Despesas: são gastos relativos aos bens e serviços consumidos no processo de
geração de receitas e manutenção dos negócios da empresa. Todas as
despesas diretamente ou indiretamente associadas à realização de receitas, as
empresas têm despesas para gerar receitas e não para produzir seus bens e
serviços.

As despesas em uma propriedade rural podem ser incorridas diretamente ou indiretamente: nas receitas de vendas diretamente podem ocorrer: impostos sobre vendas, custos das vendas, fretes e comissões: nas receitas de vendas indiretamente podem ser: aluguel de pasto, depreciação de móveis e utensílios, despesas gerais de vendas (PADOVEZE 2003, p.18).

Despesas são de um modo em geral gastos ligados a área administrativa e comercial da empresa, são os gastos para vender o produto, ou seja, para comercializar os animais da propriedade rural. A despesa significa o consumo do custo e portanto quando ocorre é redutora do lucro (PADOVEZE 2003, p.18). 
Custo do gado bovino rastreado da fazenda cachoeira e outras em Tangará da Serra: uso do custeio variável

Ederson Junio Pelissari, Laércio Juarez Melz, Cleiton Franco, Priscila Meliane Leite dos Anjos

Para Padoveze (2003, p.17) “investimento são os gastos em ativos ou despesas e custos que serão imobilizados ou diferidos. São gastos ativados em função de sua vida útil ou de benefícios futuros".

Os investimentos na atividade pecuária vêm ajudar a compor atividade, ou seja, é preciso ter para manter a propriedade rural, um bom exemplo de investimento pode ser o curral para manejo do gado em toda a vida do animal (PADOVEZE 2003, p.17).

Os investimentos são convertidos em custos por meio do processo de depreciação. Marion (2007b, p.65) define que: “depreciação seria sinônimo de amortização, em sentido amplo, porém sendo aplicada somente aos bens tangíveis, como máquinas, equipamentos, móveis, utensílios, edifícios etc".

No processo produtivo de gado de corte, os animais não sofrerão depreciação, devido esse termo ser aplicados em outras modalidades de criação como, por exemplo, a criação de reprodutores. (MARION 2007b, p.70).

Tratando-se de animais que são usados na propriedade como sendo de trabalho, estes deverão ser classificados no ativo permanente tangível de vida útil limitada, tendo que observar a "perda de capacidade normal de trabalho - assemelhando-se nesse aspecto à uma máquina ou equipamento qualquer” (MARION 2007b, p.70).

Marion (2007b, p.70). relata que:

No período de crescimento do gado destinado à reprodução, não haverá, evidentemente, depreciação. A vida útil do rebanho de reprodução, para efeito de depreciação, será contada a partir do momento em que estiver em condições de reprodução (estado adulto). Já em plena reprodução, o animal, principalmente o touro, tende a atingir um estágio de máxima eficiência para, a seguir, iniciar processo de declínio, até perder sua utilidade para esse fim. Não há dúvida de que o ideal seria detectar o inicio do processo de declínio para iniciar a depreciação. Todavia, como na prática não é fácil detectar esse ponto, normalmente a depreciação é iniciada no momento em que o rebanho começa a ser utilizado para a reprodução. Aliem-se a esse argumento o fato de que o gado envelhece a cada ano que passa e há necessidade de distribuição de seu custo.

"Outro problema é determinar a vida útil do rebanho. Podem-se observar variações em regiões próximas, que oscilam de quatro a dez anos (após o início da atividade de reprodução)" (MARION 2007b, p.70).

"Ressalte-se, todavia que o veterinário é a pessoa mais indicada para determinar a vida útil do gado reprodutor" (MARION 2007b, p.70).

Segundo o autor, a estimativa de vida útil do rebanho pode ser: 
Custo do gado bovino rastreado da fazenda cachoeira e outras em Tangará da Serra: uso do custeio variável

Ederson Junio Pelissari, Laércio Juarez Melz, Cleiton Franco, Priscila Meliane Leite dos Anjos

Quadro 1. Estimativa de vida do rebanho bovino.

\begin{tabular}{|c|c|}
\hline Gado reprodutor mestiço & cinco anos \\
\hline Gado matriz mestiça & sete anos \\
\hline Gado reprodutor puro & oito anos \\
\hline Gado matriz pura & dez anos \\
\hline
\end{tabular}

Fonte: Marion (2007b).

A depreciação deveria considerar o peso do animal abatido no frigorífico multiplicado pelo preço obtido pela arroba, em ocasião de sua venda após ser castrado e descartado de reprodutor e engordado para abate, assim poderia se obter o valor real do animal podendo ser determinado sua depreciação (MARION, 2007b, p.71).

A depreciação também não deve ser confundida com perda. Deve-se observar a relevância do valor envolvido ao se falar em perdas, pois nem sempre pode ser lançado como se observa. Sabendo que não deve ser confundido perda com despesa e nem mesmo com custo, devido a uma característica de ser anormal ao processo de produção e involuntário (MARTINS 2003, p.26).

Podendo ser citado aqui alguns exemplos de perda: perdas em incêndios, obsoletismo de estoque entre outros. Onde estes deverão ser lançados diretamente na conta de resultados da empresa, igualmente como as despesas (MARTINS 2003, p.26).

Perez Junior, Oliveira e Costa (2003,p.17) relatam que:

\begin{abstract}
Perdas são gastos anormais ou involuntários que não geram um novo bem ou serviço e tampouco receitas e são apropriadas diretamente no resultado do período em que ocorrem. Esses gastos não mantêm nenhuma relação com a operação da empresa e geralmente ocorrem de fatos não previstos. Exemplos: Gastos incorridos em períodos de paralisação de produção devido à falta de insumos;Problemas com equipamentos, greves, enchentes, inundações, sinistros etc.
\end{abstract}

Se houver perda anormal, em caso, por exemplo, de incêndio, roubo, enchente etc. no almoxarifado, os valores correspondentes não deverão ser tratados como custos de produção, mas levados diretamente ao resultado do exercício (MEGLIORINI, 2007, p.22)

Padoveze (2003, p.18) demonstra que:

São fatos ocorridos em situações excepcionais, que fogem à normalidade das operações da empresa. São considerados não-operacionais e não devem fazer parte dos custos de produção. São eventos econômicos negativos ao 
Custo do gado bovino rastreado da fazenda cachoeira e outras em Tangará da Serra: uso do custeio variável

Ederson Junio Pelissari, Laércio Juarez Melz, Cleiton Franco, Priscila Meliane Leite dos Anjos

patrimônio empresarial, não habituais e eventuais, tais como deterioração anormal de ativos, perdas de créditos excepcionais, capacidade ociosa anormal etc.

\subsection{Método de custeio variável}

O método de custeio define como os custos de produção serão atribuídos ao produto final. O método que a empresa utiliza depende da finalidade. Quando a finalidade é atender a legislação fiscal, utilizam, com frequência, um método baseado em absorção. Quando a finalidade é facilitar as decisões empresariais é interessante utilizar custeios baseados em volume, como o custeio variável (PADOVEZE, 2003).

Padoveze(2003, p.77) relata que "a mensuração da receita dos produtos e serviços, recursos, atividades da empresa tem como fundamento o preço de mercado".

Padoveze (2003, p.77), afirma, também, que:

O método de mensuração do custo está fundamentalmente ligado a três questões:os gastos (custos e despesas) que devem fazer parte da apuração do custo dos recursos, produtos, serviços, atividades ou departamentos e, por conseqüência - os custos de um recurso, bem produto ou serviço final que devem ser ativados enquanto esses bens estão em estoque (enquanto não são vendidos); a definição da metodologia de cálculo e a apuração do custo unitário dos produtos e serviços.

O custeio variável considera separadamente os custos variáveis e fixos. Nessa perspectiva, Crepaldi (2005, p. 100) afirma que:

Custos variáveis variam proporcionalmente ao volume produzido. Exemplo insumos, embalagens. Se não houver quantidade produzida, o custo variável será nulo. Os custos variáveis aumentam à medida que aumentam a produção agrícola. Outros exemplos: insumos indiretos consumidos, depreciação dos equipamentos agrícolas, quando essa for feita em função das horas máquinas trabalhadas, gastos com horas extras na produção agrícola etc.

Crepaldi (2005) define que: os custos fixos não são alocados ao custo do produto, por motivo de existirem mesmo não havendo produção.

Ainda Padoveze (2003.p53), afirma que "Os custos diretos e indiretos podem ser classificados em fixos e variáveis, quando tomamos como referencial o seu comportamento em relação ao volume de produção (ou vendas)',

Megliorini (2007, p.125) aponta onde o custeio variável pode auxiliar e demonstra qual suas vantagens e desvantagens.

Quadro 2. Vantagens e desvantagens do custeio variável.

\begin{tabular}{|l|l|}
\hline Vantagens & Desvantagens \\
\hline
\end{tabular}


Custo do gado bovino rastreado da fazenda cachoeira e outras em Tangará da Serra: uso do custeio variável

Ederson Junio Pelissari, Laércio Juarez Melz, Cleiton Franco, Priscila Meliane Leite dos Anjos

1.Pode auxiliar

- na definição do preço de venda baseado em custos, em relação ao valor mínimo a ser praticado;

- na decisão de como empregar recursos limitados de maneira mais vantajosa;

- na identificação dos produtos mais rentáveis;

- na decisão de produzir ou comprar um item

\section{Desvantagens}

As principais desvantagens do custeio variável estão relacionadas ao crescimento da proporção dos custos fixos na estrutura de custos das empresas, em decorrência de contínuos investimentos em capacitação tecnológica e produtiva, bem como à correta identificação dos custos variáveis, em especial quando a mesma conta contempla os custos fixos e variáveis.

Fonte: Adaptado de Megliorini (2007, p.125).

\subsection{Características da bovinocultura de corte}

Pode-se definir Bovinocultura de corte sendo o processo de criação e engorda de bovinos, até o momento em que os animais são comercializados e abatidos, sendo essa prática definida realizada com finalidade e destinação dos animais prontos para o abate (MARION 2007a, p.20).

Sempre ocorre no decorrer do ano uma variação no preço ofertado na arroba para a venda, devido a oferta e demanda oferecida dos animais, as características raciais dos animais e localização dentro do país, também mude o valor ofertado pela arroba dos animais (Marion 2007a, p.20) afirma que a pecuária é a "arte de criar e tratar gado"

Gados, segundo (Marion 2007a, p.20) "são animais geralmente criados no campo, para serviços de lavoura, para consumo domestico ou para fins industriais e comerciais". Como exemplos de gado podem-se citar: bovinos, bubalinos, caprinos, eqüinos, ovinos, muares etc." Cria-se gado bovino com as finalidade de trabalho, reprodução, corte ou leite (MARION, 2007a, p.20).

A atividade da bovinocultura alcança os mercados internos e externos, onde os produtores tendo a mão o seu estoque de animais prontos podem comercializá-los, sendo os indicadores de mercado do preço da arroba regulamentados pela bolsa de valores.

A produção de bovinos acontece em três fases e pode ser realizada, combinando as fases, em até seis especialidades (Quadro 3). A combinação das fases de cria e engorda não pode existir sem a fase de recria. Nesta combinação há o ciclo completo de produção.

Quadro 3. Fases e especializações da criação de bovinos. 
Custo do gado bovino rastreado da fazenda cachoeira e outras em Tangará da Serra: uso do custeio variável

Ederson Junio Pelissari, Laércio Juarez Melz, Cleiton Franco, Priscila Meliane Leite dos Anjos

\begin{tabular}{|c|c|c|c|}
\hline \multirow{2}{*}{ Fases } & \multicolumn{3}{|c|}{ Especialidades e combinações } \\
\cline { 2 - 4 } & Cria & Recria & Engorda \\
\hline \multirow{2}{*}{ Cria } & Cria & Cria-recria & Cria-recria-engorda \\
\hline \multirow{2}{*}{ Recria } & Cria-recria & Recria & Cria-recria-engorda \\
\hline & Cria-recria-engorda & Recria-engorda & Cria-recria-engorda \\
\end{tabular}

Fonte: Adaptado de Marion (2007b, p.106).

Marion (2007b, p.106) conceitua as fases de produção:

Cria: a atividade básica é a produção de bezerros que só serão vendidos após o desmame. Normalmente, a matriz (de boa fertilidade) produz um bezerro por ano.

Recria: a atividade básica é a partir do bezerro adquirido, a produção e a venda do novilho magro para a engorda.

Engorda: a atividade básica é, a partir do novilho magro adquirido, a produção e a venda do novilho gordo.

Os sistemas de produção (manejo) do bovino podem ser divididos basicamente em extensivo, semi-intensivo e intensivo (Quadro 4).

Quadro 4. Sistemas de produção de gado bovino.

\begin{tabular}{|l|l|}
\hline Sistema extensivo: & $\begin{array}{l}\text { Geralmente, os animais são mantidos em pastos nativos ou cultivados, na } \\
\text { dependência exclusiva dos recursos naturais. Esse sistema caracteriza-se por } \\
\text { baixa lotação, variando de } 0,4 \text { a } 0,8 \text { UA/ha/ano, em áreas contiguas sem } \\
\text { planejamento adequado de lotação e disponibilidade de forragens. O manejo } \\
\text { sanitário baseia-se simplesmente em calendários oficiais de vacinação da } \\
\text { região em que está inserida a propriedade. O manejo zootécnico é ausente ou } \\
\text { pouco presente, não se preocupando com o suprimento de forragens no } \\
\text { período adverso do ano (seca). }\end{array}$ \\
\hline Sistema semi-intensivo: & $\begin{array}{l}\text { Com a inviabilidade técnica/econômica do sistema anterior à degradação das } \\
\text { forrageiras ou pastagens, o pecuarista que pretende manter-se na atividade } \\
\text { tem adotado esse método, em que se faz necessária a implantação de } \\
\text { forrageiras, as quais sofrem um pastoreio racional, através de algumas } \\
\text { subdivisões das pastagens, o que leva a uma maior capacidade de suporte por } \\
\text { unidade de área, podendo atingir até 4,0 UA/ha/ano. Há um manejo mais } \\
\text { adequado do rebanho além das vacinações obrigatórias, há vermifugação, } \\
\text { mineralização e um acompanhamento zootécnico do rebanho. }\end{array}$ \\
\hline Sistema intensivo: & $\begin{array}{l}\text { Com o aumento da população e, conseqüentemente, com a redução da área } \\
\text { útil, com o desejo de obter maior produtividade, aumentando a rentabilidade, } \\
\text { com o desenvolvimento tecnológico e da assistência técnica, está-se atingindo } \\
\text { paulatinamente o sistema intensivo. }\end{array}$ \\
\hline
\end{tabular}

Fonte: Adaptado Marion (2007a,p.20). 
Custo do gado bovino rastreado da fazenda cachoeira e outras em Tangará da Serra: uso do custeio variável

Ederson Junio Pelissari, Laércio Juarez Melz, Cleiton Franco, Priscila Meliane Leite dos Anjos

Busca-se na atividade pecuária formas onde o gado ganhe peso o mais rápido possível, e fique o menor tempo na propriedade onde o produtor pode usar 2 (dois) tipos de pastagem, sendo elas a pastagem natural, ou seja, nativo da região pastoreada e também a pastagem artificial, sendo essa a mais comum e utilizada pelos pecuaristas da região, podendo serem realizados na forma de pastejo continuo ou rodízio (MARION, 2007a, p. 22 e 23).

\subsection{Conceitos de rastreabilidade}

"Rastreabilidade é definida como a habilidade de descrever a história, aplicação, processos ou eventos e localização, de um produto, a uma determinada organização, por meios de registros e identificação" (FATEC S/A, 2011).

"Em outras palavras, rastrear é procurar alguma coisa para saber o máximo sobre ela (o que é, de onde veio, como foi feito e pra onde foi) e assim, falar com segurança sobre o assunto sem medo de errar" (FATEC S/A, 2011).

O rastreamento de bovinos ficou bastante popular no final da década de 90, porém por não ter uma nova reguladora que atendesse o interesse dos países consumidores dos blocos econômicos, como a UE, Nafta e o MERCOSUL e outros, onde os produtores Brasileiros realizavam o rastreamento de bovinos de maneira incompleta, não atendendo as exigências dos países consumidores (FATEC S/A, 2011).

"A rastreabilidade de um animal consiste no acompanhamento e registro de todos os eventos, ocorrências, manejos, ocorridas durante sua vida, desde o momento de seu nascimento ou identificação até seu abate ou morte" (SYSRASTRO, 2011)

“O objetivo da rastreabilidade é permitir, rapidamente, o resgate do histórico do produto e de seu processo de produção, do campo ao prato, atuando como mecanismo fundamental na segurança alimentar da população" (SYSRASTRO, 2011).

"O conceito da rastreabilidade propõe transparência, honestidade e permanente diálogo entre as partes envolvidas na produção, visando à satisfação do consumidor cada vez mais exigente e o estímulo para aqueles que participam do processo" (SYSRASTRO, 2011).

A Instrução Normativa 17 estabelece a Norma Operacional do Serviço de Rastreabilidade da Cadeia Produtiva de Bovinos e Bubalinos (SISBOV), aplicável a todas as fases de produção, transformação, distribuição e dos serviços agropecuários. As 
Custo do gado bovino rastreado da fazenda cachoeira e outras em Tangará da Serra: uso do custeio variável

Ederson Junio Pelissari, Laércio Juarez Melz, Cleiton Franco, Priscila Meliane Leite dos Anjos

normas evoluíram, desde 1996, a partir do surto de Encefalopatia espongiforme bovina (BSG), conhecida como doença da vaca louca, na Europa (Quadro 5).

Quadro 5. Cronologia dos fatos ligados à rastreabilidade no Brasil

\begin{tabular}{|c|l|}
\hline Período & \multicolumn{1}{c|}{ Evolução das normas de rastreabilidade } \\
\hline 1996 & Foco da doença da "vaca louca" - Acontecido na União Européia. \\
\hline 2000 & Novos casos da doença da "vaca louca" - Acontecido na União Européia. \\
\hline 2000 & Brasil se desperta para atender as normas sanitárias para exportação, carne bovina. \\
\hline 2000 & $\begin{array}{l}\text { Preocupação dos países doenças parasitárias e consumo de outros tipos de carnes pelos } \\
\text { consumidores. }\end{array}$ \\
\hline 2002 & Instrução Normativa Mapa n01 -Inicio da normatização da rastreabilidade bovina no Brasil \\
\hline 2003 & Instrução Normativa SDA n47 - Atualização de normas técnicas. \\
\hline 2004 & Instrução Normativa SDA n ${ }^{\circ} 52-$ Atualização de normas técnicas. \\
\hline 2006 & $\begin{array}{l}\text { Instrução Normativa MAPA n }{ }^{\circ} 17 \text { - Válida para todos os procedimentos de rastreabilidade até } \\
\text { a data atual - 2011. }\end{array}$ \\
\hline
\end{tabular}

Fonte: Sysrastro (2011), Figueira e Miranda (2011)

\section{METODOLOGIA}

Esta pesquisa foi realizada com dados primários e também secundários. Os dados secundários foram observados através de pesquisa bibliográfica e telematizada. Foram consultados a Instrução Normativa 17 - SISBOV, de dezembro de 2006, sites de referências e artigos que venham tratar sobre o assunto pesquisado a rastreabilidade bovina e custo variável de produção (RIBEIRO; TORRES; ROCHA, 2005, p.56).

O espaço de análise ficou delimitado em quatro dimensões: tempo, elo da cadeia produtiva, produto e local (GUANZIROLI; BUAINAIN; SOUZA FILHO, 2008). O período de realização da pesquisa foi de 02 de fevereiro de 2011 à 31 de agosto de 2011. O elo da cadeia produtiva analisado foi a produção pecuária. O produto analisado foi gado bovino rastreado. O local delimitado foi Tangará da Serra-MT.

Este trabalho obteve como base o método científico de pesquisa quanto à forma de estudo descritiva, quando foi descrito todo o processo de produção de gado Rastreado em Tangará da Serra e foi realizado também a caracterização dos custos variáveis aplicados na propriedade rural (RIBEIRO; TORRES; ROCHA, 2005, p.52).

Foi realizada uma pesquisa através de questionário com questões abertas e fechadas onde foi pesquisado se os produtores conhecem e controlam seus custos de produção por meio de entrevista (RIBEIRO; TORRES; ROCHA, 2005, p.53).

Tabela 1. Propriedade rastreada, estratificada por número de animais na propriedade, em quantidade de respostas.

\begin{tabular}{lr}
\hline \multicolumn{1}{c}{ Quantidade de Animais } & \multicolumn{1}{c}{ Número de entrevistados } \\
\hline Volume 2, Número 3 & Revista UNEMAT de Contabilidade \\
Jan./Jun. 2013 & ISSN: 2316-8072
\end{tabular}


Custo do gado bovino rastreado da fazenda cachoeira e outras em Tangará da Serra: uso do custeio variável

Ederson Junio Pelissari, Laércio Juarez Melz, Cleiton Franco, Priscila Meliane Leite dos Anjos

$\begin{array}{cc}501 \text { a } 1000 & 2 \\ 1001 \text { a } 5000 & 12 \\ \text { acima de } 5001 & 3 \\ \text { Total Geral } & 17\end{array}$

A lista de propriedades certificadas para União Européia foi obtida pelo site da European Comission (2011). Neste artigo foram localizadas 22 propriedades. Dezessete propriedades responderam ao questionário perguntado. As outras 5 propriedades restantes, 3 não havia animais no momento da entrevista e as outras 2 se recusaram a responder a entrevista. A tabela 1 demonstra o cenário que este artigo vem tratar, sabendo assim que das 17 propriedades entrevistadas qual é a quantidade aproximada de animais em cada uma delas, onde a pergunta principal era se a propriedade era rastreada e se cumpria todas as exigências impostas pela IN 17. As respostas por categoria foram às seguintes: de 501 a 1000 animais 2 propriedades, de 1001 a 5000 animais 12 propriedades e acima de 5001 animais 3 propriedades.

\section{RESULTADOS E DISCUSSÕES}

\subsection{O processo de produção}

No quadro 6 observam-se as diferenças de cada etapa entre os animais rastreados e não rastreados, desde a sanidade até os cuidados com o controle dos animais.

Quadro 6. O processo de produção de gado rastreado e não rastreado em um ciclo operacional de 27 meses de permanência na propriedade rural.

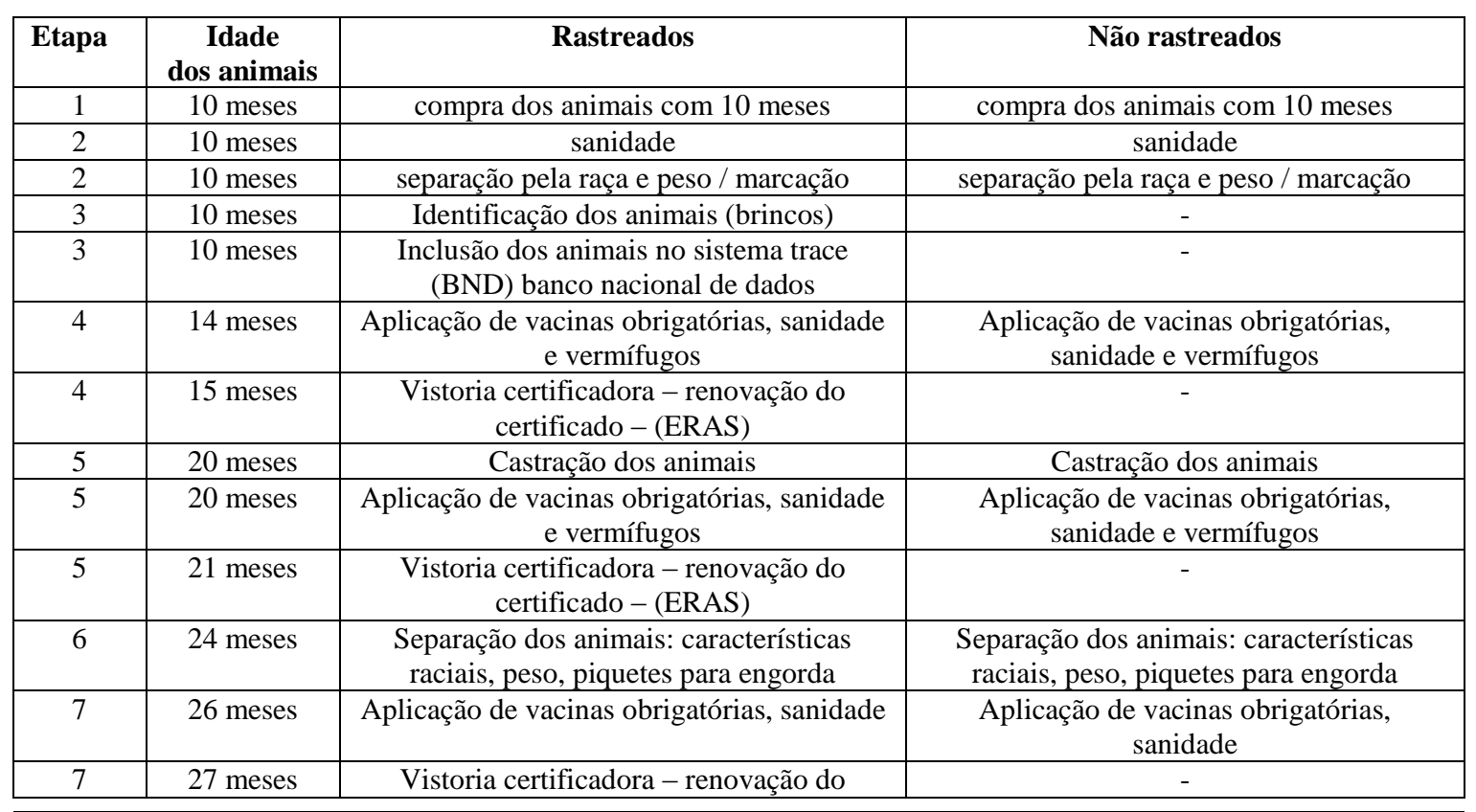

Volume 2, Número 3

Revista UNEMAT de Contabilidade

Jan./Jun. 2013

ISSN: 2316-8072 
Custo do gado bovino rastreado da fazenda cachoeira e outras em Tangará da Serra: uso do custeio variável

Ederson Junio Pelissari, Laércio Juarez Melz, Cleiton Franco, Priscila Meliane Leite dos Anjos

\begin{tabular}{|c|c|c|c|}
\hline & & certificado - (ERAS) & \\
\hline 8 & 32 meses & Aplicação de vacinas obrigatórias, sanidade & $\begin{array}{c}\text { Aplicação de vacinas obrigatórias, } \\
\text { sanidade }\end{array}$ \\
\hline 8 & 33 meses & $\begin{array}{c}\text { Vistoria certificadora - renovação do } \\
\text { certificado - (ERAS) }\end{array}$ & Animais prontos para abate \\
\hline 8 & 36 meses & Animais prontos para abate & Abara \\
\hline
\end{tabular}

O ciclo de vida dos animais dentro da fazenda é de 27 meses e é distribuído em 8 etapas, onde são realizados todo o manejo da parte física e a sanidade e controle dos animais, fazendo um comparativo entre a modalidade rastreado e não rastreado, é o que se descreve nas etapas abaixo:

$1^{\circ}$ Etapa: Nesta etapa é realizada a aquisição dos animais com 10 meses em média onde eles são adquiridos de produtores da região, sendo eles pequenos médios e grandes produtores que disponibilizam os animais a preço de mercado, sendo realizada essa etapa nas duas modalidades aqui estudadas, animais rastreados ou não rastreados.

$2^{\circ}$ Etapa: Nesta etapa é quando os animais chegam à propriedade e são realizados todos os manejos sanitários necessários para a atividade pecuária sendo eles: aplicação de vacinas, Anti-raiva, Aftosa, e clostridiose. Nessa etapa é normal realizar a separação dos animais pelas suas características raciais e também pelo seu peso e também é realizada a marcação dos animais a fogo, realizado essa etapa da mesma forma para as duas modalidades aqui estudadas.

$3^{\circ}$ Etapa: Já nesta etapa é onde começa as diferenças entre as modalidades aqui estudadas, e onde é realizada a identificação, o rastreamento e cadastramento dos animais no banco nacional de dados (BND), onde após três dias os animais são enviados para o sistema nacional, sendo que o método utilizado para o controle nacional dos animais pelo Ministério da Agricultura Pecuária e Abastecimento (MAPA), desta forma é colocado os brincos identificadores nos animais, realizados através de um link disponibilizado pela empresa certificadora responsável para o produtor rural, onde os animais deverão permanecer na propriedade durante uma noventena, prazo esse determinado e entendido que serve para que o animal fique repousando e se recupere de todo e qualquer stress sofrido no manejo e transporte dos mesmos. Podendo ser realizada a inclusão dos mesmos de duas formas, onde o produtor assume a responsabilidade e realiza a inclusão dos animais no banco de dados ou repassa as informações e toda a documentação necessária para a certificadora responsável processar os dados. Assim, com os animais já identificados é realizada a primeira vistoria na propriedade feita pela certificadora responsável que deverá ser realizada a 
cada seis meses, onde é verificada toda a documentação e assinaturas do produtor, e também onde é colhida a numeração de trezentos animais e mais trezentos são apenas observados se estão com os elementos identificadores, e demais exigências contidas na normativa 17 que dita todas as regras necessárias para uma propriedade rastreada. Já em uma propriedade sem o uso da rastreabilidade não se aplica nenhuma parte dessa etapa.

$4^{\circ}$ Etapa: Ao completarem 15 meses os animais passam pela primeira aplicação de vermífugos para controle de vermes e parasitas. E passam pela segunda vistoria de renovação de certificado da propriedade (ERAS), observando seiscentas cabeças da mesma forma da primeira vistoria. Em uma propriedade não rastreada os animais passariam apenas pelo manejo sanitário.

$5^{\circ}$ Etapa: É nesta fase que ocorre um índice de perda de animais maior que a média devido ao período da castração, onde os animais passam por essa intervenção para que os mesmos possam ganhar peso com maior agilidade e também consequentemente melhorar o manejo. Cumprindo o manejo sanitário e o calendário de vacinação obrigatória também é realizada a vacinação dos animais da propriedade. $\mathrm{E}$ também realizados a terceira vistoria de renovação do certificado (ERAS) propriedade, onde é observada a continuidade do controle e sanidade dos animais pelo produtor, podendo ser renovado ou não, dependendo da organização da propriedade rastreada.

$6^{\circ}$ Etapa: De suma importância, pois é nesta fase que é realizada a segunda e última separação dos animais de acordo com suas características raciais e peso dos animais, deixando assim um padrão nos pastos e na propriedade, preferencialmente os animais ficam em pastagens de melhor qualidade buscando ganhar peso e assim aguardando um futuro abate. Não há diferença entre as duas modalidades pesquisadas nesta fase.

$7^{\circ}$ Etapa: $\mathrm{O}$ produtor realiza nesta fase a vacinação obrigatória dos animais e também todo o manejo sanitário necessário, desde o controle de parasitas e moscas que prejudicam e atacam os animais. Sendo realizada a vistoria para renovação do certificado (ERAS) da propriedade, onde só será feito a renovação através da certificadora responsável, se o produtor estiver com a documentação e controles dos animais de forma regular. Para animais não rastreados é realizada somente a parte da sanidade dos animais. O mesmo processo acontece na $8^{\circ}$ Etapa, para os dois sistemas de manejo, com 33 meses. 
Custo do gado bovino rastreado da fazenda cachoeira e outras em Tangará da Serra: uso do custeio variável

Ederson Junio Pelissari, Laércio Juarez Melz, Cleiton Franco, Priscila Meliane Leite dos Anjos

$8^{\circ}$ Etapa: Nesta etapa os animais já estão pronto para o abate, isso preferencialmente deve ocorrer nos meses de julho a novembro de cada ano, onde a procura pelos animais terminados aumentam devido à falta de pastagens, sendo que dessa forma o produtor pode conseguir um diferencial no valor da arroba do boi se comparado aos outros meses do ano onde a oferta tende a ser mais propícia e esperada. Nesta etapa não há diferenças entre às duas modalidades aqui estudadas.

\subsection{Custo de produção de gado rastreado}

Quando se trata de custos devem-se mensurar todas as despesas e gastos adequados para a produção do gado rastreado devendo ser considerado o custo de produção. É necessário elencar itens que compõem o custo de produção do gado no qual será apresentado na tabela 2.

Tabela 2. Custo do da rastreabilidade de 3000 animais em um período de 27 meses em uma propriedade rural em Tangará da Serra-MT.

\begin{tabular}{lccr}
\hline \multicolumn{1}{c}{ Descrição } & Valores & Quantidades & Total \\
\hline Aquisição brincos & 1,38 & 3000 & $4.140,00$ \\
Certificação animais & 2,00 & 3000 & $6.000,00$ \\
Certificação propriedade & $1.200,00$ & 5 & $6.000,00$ \\
\multicolumn{1}{c}{ Total Geral } & & & $\mathbf{1 6 . 1 4 0 , 0 0}$ \\
\hline
\end{tabular}

Os custos apresentados são aplicados no período de 27 meses, período em que os animais permanecem na propriedade. A rastreabilidade tem relevância em se tratando de custos, pois começa na aquisição dos brincos a $\mathrm{R} \$ 1,38$ cada, preço que representa um conjunto de elementos identificadores contendo: 1 brinco, 1 botton e 1 machinho. Também é realizada a certificação dos animais onde é despendido o custo de $\mathrm{R} \$ 2,00$ por animal, obrigatório para a impressão do Documento de Identificação Animal (DIA), que é impresso em papel 90g com marca d'água SISBOV filigramado, obrigatório segundo a (IN 17), impossibilitando assim a impressão pelo produtor, adulteração ou dos dados dos animais pelo mesmo, onde são impressas todas as características do animal, sexo, raça e numeração que identificam a propriedade, o produtor e quais são as datas de inclusão e liberação para abate dos animais, sendo considerada uma certidão de nascimento do animal para o SISBOV. A propriedade deve passar pela vistoria da certificadora a cada 6 meses, onde a certificadora verifica as condições físicas e a sanidade dos animais, e o mais importante a continuidade e o seguimento da Instrução Normativa 17 , onde é cobrado em média uma taxa de $\mathrm{R} \$ 1.200,00$, de renovação do certificado ERAS da propriedade. 
Custo do gado bovino rastreado da fazenda cachoeira e outras em Tangará da Serra: uso do custeio variável

Ederson Junio Pelissari, Laércio Juarez Melz, Cleiton Franco, Priscila Meliane Leite dos Anjos

Considera-se como gastos com mão-de-obra aquelas que são contratados, encargos sociais, assistências podendo ser, agronômica, contábil, veterinária, zootécnica, ou consultorias ocasionais; Considera-se também como gasto na propriedade a mão-de-obra eventual, mão-de-obra familiar, além de outras. Na fazenda cachoeira são registrados 7 funcionários, onde 6 são vaqueiros, e um é o gerente geral responsável pela fazenda.

Tabela 3. Mão-de-obra usada na propriedade.

\begin{tabular}{lccc}
\hline \multicolumn{1}{c}{ Descrição } & Valores & Quantidades & Total \\
\hline Salários Vaqueiros & 800,00 & 6 & $4.800,00$ \\
$13^{\circ}$ Sal & 66,67 & 6 & 400,02 \\
Férias & 66,67 & 6 & 400,02 \\
$1 / 3$ & 22,22 & 6 & 133,32 \\
Gerente Geral & $2.000,00$ & 1 & $2.000,00$ \\
$13^{\circ}$ Sal & 166,67 & 1 & 166,67 \\
Férias & 166,67 & 1 & 166,67 \\
$1 / 3$ & 55,56 & 1 & 55,56 \\
FGTS 8\% & $8.122,26$ & & 649,78 \\
INSS 2.7\% & $8.122,26$ & & 219,30 \\
Total & & & $\mathbf{8 . 9 9 1 , 3 4}$ \\
\hline
\end{tabular}

No caso da fazenda cachoeira as despesas agronômicas, veterinária e zootécnica ou consultorias ocasionais, são prestadas de forma indireta, ou seja, foi fixada uma parceria entre uma empresa de revenda de produtos agropecuários, e esta empresa presta todas as assessorias necessárias sem custo adicional na aquisição dos produtos.

Para se obter os gastos com alimentação devem-se considerar todos os tipos de alimentos oferecidos aos animais.

Em relação à sanidade dos animais podem-se citar alguns exemplos de itens que são exemplos desse grupo: vermífugos, vacina contra aftosa, vacina contra carbúnculo, vacina contra raiva, mosquicidas e mata-bicheiras (tabela 3 ).

Tabela 4. Valores gastos com sanidade total para 3000 animais, no ciclo, em $\mathbf{R} \$$.

\begin{tabular}{cccc}
\hline Descrição & Valores & Quantidades / doses & Total \\
\hline Vermífugos & 0,60 & 2 & $3.537,60$ \\
Vac. Aftosa & 1,00 & 3 & $8.844,00$ \\
Vac. Carbúnculo & 0,60 & 1 & $1.768,80$ \\
Vac. Raiva & 0,30 & 1 & 884,40 \\
Mosquicida/mata-bicheiras & 0,67 & 2 & $3.950,32$ \\
Total & & & $\mathbf{1 8 . 9 8 5 , 1 2}$ \\
\hline
\end{tabular}

Na tabela 3 verifica-se a descrição dos itens e produtos utilizados na sanidade do gado na propriedade rural; A utilização dos vermífugos ocorre em duas fases diferentes, quando os animais estão com quatorze meses e também logo após a castração. Já as vacinas obrigatórias são realizadas em três fases, de acordo com o calendário de vacinação estabelecido pelo INDEA-MT e pela legislação do estado, onde 
Custo do gado bovino rastreado da fazenda cachoeira e outras em Tangará da Serra: uso do custeio variável

Ederson Junio Pelissari, Laércio Juarez Melz, Cleiton Franco, Priscila Meliane Leite dos Anjos

animais de 00 a 24 meses devem ser vacinados sempre no mês de maio de cada ano, e no mês de novembro de cada ano todo o rebanho da propriedade deve ser vacinado, chamado assim de mamando a caducando.

Já as vacinas de carbúnculo e raiva são realizadas de acordo com a necessidade da região, pois sempre que surge um surto o órgão regulamentador INDEA-MT, notifica a propriedade e obriga a sua aplicação sob pena de multa ao produtor, sendo que o utilizado na fazenda estudada é a aplicação assim que os animais chegam à propriedade. Já os Mosquicidas são pulverizados junto com a vacinação do mês de novembro, e os mata-bicheiras são utilizados de acordo com a necessidade dos animais.

Na tabela 4 verificam-se os dados de um modulo de 3000 mil animais, onde estão colocados dentro de um período de 27 meses todos os manejos e sanidades e custos envolvidos no sistema de produção pecuário da fazenda cachoeira. Consideraram-se custos variáveis: custo de aquisição, rastreabilidade, alimentação, sanidade e morte. Os custos de aquisição, rastreabilidade, alimentação e sanidade são realizados por cabeça, sendo, portanto, os custos variáveis do rebanho. A o custo de morte de animais foi atribuído por percentual, de acordo com os registros históricos da fazenda, 1,6\% ao ano. Além da do custo da mortalidade dos animais, também a mão-deobra e depreciação são custos fixos do rebanho, pois são realizados por ano.

Tabela 5. Custos de produção do gado rastreado, entre 10 e 36 meses de idade, em R\$.

\begin{tabular}{|c|c|c|c|c|c|c|c|c|c|c|c|}
\hline Meses & Cabeças & Aquisição & Rast. & Alim. & San. & Morte & Mo & Depr. & Total & Acum. & Unitário \\
\hline 10 & 3000 & $1.920 .000,00$ & $11.340,00$ & $36.000,00$ & $4.218,90$ & - & $8.991,34$ & 833,33 & $1.981 .383,57$ & $1.981 .383,57$ & 660,46 \\
\hline 11 & 2996 & - & - & $35.952,00$ & - & $2.641,84$ & $8.991,34$ & 833,33 & $48.418,52$ & $2.029 .802,09$ & 677,50 \\
\hline 12 & 2992 & - & - & $35.904,00$ & - & $2.710,02$ & $8.991,34$ & 833,33 & $48.438,69$ & $2.078 .240,78$ & 694,60 \\
\hline 13 & 2988 & - & - & $35.856,00$ & - & $2.778,40$ & $8.991,34$ & 833,33 & $48.459,07$ & $2.126 .699,85$ & 711,75 \\
\hline 14 & 2984 & - & - & $35.808,00$ & $4.408,20$ & $2.846,99$ & $8.991,34$ & 833,33 & $52.887,86$ & $2.179 .587,71$ & 730,42 \\
\hline 15 & 2980 & - & $1.200,00$ & $35.760,00$ & - & $2.921,70$ & $8.991,34$ & 833,33 & $49.706,37$ & $2.229 .294,08$ & 748,09 \\
\hline 16 & 2976 & - & - & $35.712,00$ & - & $2.992,34$ & $8.991,34$ & 833,33 & $48.529,01$ & $2.277 .823,10$ & 765,40 \\
\hline 17 & 2972 & - & - & $35.664,00$ & - & $3.061,59$ & $8.991,34$ & 833,33 & $48.550,26$ & $2.326 .373,36$ & 782,76 \\
\hline 18 & 2968 & - & - & $35.616,00$ & - & $3.131,05$ & $8.991,34$ & 833,33 & $48.571,73$ & $2.374 .945,09$ & 800,18 \\
\hline 19 & 2964 & - & - & $35.568,00$ & - & $3.200,73$ & $8.991,34$ & 833,33 & $48.593,41$ & $2.423 .538,50$ & 817,66 \\
\hline 20 & 2960 & - & - & $35.520,00$ & $4.029,80$ & $3.270,63$ & $8.991,34$ & 833,33 & $52.645,11$ & $2.476 .183,60$ & 836,55 \\
\hline 21 & 2956 & - & $1.200,00$ & $35.472,00$ & - & $3.346,19$ & $8.991,34$ & 833,33 & $49.842,87$ & $2.526 .026,47$ & 854,54 \\
\hline 22 & 2952 & - & - & $35.424,00$ & - & $3.418,17$ & $8.991,34$ & 833,33 & $48.666,84$ & $2.574 .693,31$ & 872,19 \\
\hline 23 & 2948 & - & - & $35.376,00$ & - & $3.488,74$ & $8.991,34$ & 833,33 & $48.689,42$ & $2.623 .382,73$ & 889,89 \\
\hline 24 & 2944 & - & - & $35.328,00$ & - & $3.559,54$ & $8.991,34$ & 833,33 & $48.712,22$ & $2.672 .094,95$ & 907,64 \\
\hline 25 & 2940 & - & - & $35.280,00$ & - & $3.630,56$ & $8.991,34$ & 833,33 & $48.735,24$ & $2.720 .830,18$ & 925,45 \\
\hline 26 & 2936 & - & - & $35.232,00$ & $2.812,40$ & $3.701,81$ & $8.991,34$ & 833,33 & $51.570,88$ & $2.772 .401,07$ & 944,28 \\
\hline 27 & 2932 & - & $1.200,00$ & $35.184,00$ & - & $3.777,11$ & $8.991,34$ & 833,33 & $49.985,79$ & $2.822 .386,85$ & 962,61 \\
\hline 28 & 2928 & - & - & $35.136,00$ & - & $3.850,46$ & $8.991,34$ & 833,33 & $48.811,13$ & $2.871 .197,99$ & 980,60 \\
\hline 29 & 2924 & - & - & $35.088,00$ & - & $3.922,40$ & $8.991,34$ & 833,33 & $48.835,07$ & $2.920 .033,06$ & 998,64 \\
\hline 30 & 2920 & - & - & $35.040,00$ & - & $3.994,57$ & $8.991,34$ & 833,33 & $48.859,25$ & $2.968 .892,31$ & $1.016,74$ \\
\hline 31 & 2916 & - & - & $34.992,00$ & - & $4.066,98$ & $8.991,34$ & 833,33 & $48.883,65$ & $3.017 .775,96$ & $1.034,90$ \\
\hline 32 & 2912 & - & - & $34.944,00$ & $3.515,75$ & $4.139,61$ & $8.991,34$ & 833,33 & $52.424,03$ & $3.070 .199,99$ & $1.054,33$ \\
\hline 33 & 2908 & - & $1.200,00$ & $34.896,00$ & - & $4.217,31$ & $8.991,34$ & 833,33 & $50.137,98$ & $3.120 .337,97$ & $1.073,02$ \\
\hline 34 & 2904 & - & - & $34.848,00$ & - & $4.292,07$ & $8.991,34$ & 833,33 & $48.964,75$ & $3.169 .302,72$ & $1.091,36$ \\
\hline 35 & 2900 & - & - & $34.800,00$ & - & $4.365,43$ & $8.991,34$ & 833,33 & $48.990,10$ & $3.218 .292,82$ & $1.109,76$ \\
\hline 36 & 2896 & - & - & $34.752,00$ & - & $4.439,02$ & $8.991,34$ & 833,33 & $49.015,70$ & $3.267 .308,52$ & $1.128,21$ \\
\hline Total & 0 & $1.920 .000,00$ & $16.140,00$ & $955.152,00$ & $18.985,05$ & $91.765,29$ & $242.766,18$ & $22.500,00$ & $3.267 .308,52$ & - & - \\
\hline Unitário & 0 & 640,00 & 5,38 & 318,38 & 6,33 & 30,59 & 80,92 & 7,50 & $1.128,21$ & - & - \\
\hline
\end{tabular}


$\mathrm{Na}$ tabela 4, podem-se verificar detalhadamente os custos de produção do gado rastreado na propriedade, tendo como base um modulo de 3000 mil animais, desde os custos de aquisição que está incluído o valor do animal e também o custo de transporte até a propriedade e comissões do intermediador do negócio. A rastreabilidade está todo o custo de compra dos elementos identificadores e inclusão dos mesmos nos órgãos competentes, até as vistorias e certificações da propriedade ocorridas semestralmente.

A alimentação dos animais foi calculada de acordo com o custo do aluguel mensal e toda parte de mineralização do gado na propriedade. Já o custo com a sanidade envolve desde quando os animais chegam à fazenda até o dia do abate, onde estão incluídos todos os custos com vacinas, vermífugos, mosquicidas e mata-bicheiras utilizados no período. Já as mortes ocorridas na propriedade são de 1,6\% ao ano, levando uma perda de quatro animais em média por mês, essas perdas ocorrem devido a acidentes sofridos no período, descargas elétricas, acidentes ofídicos, fraturas, ingestão de corpo estranho, e com maiores índices quando é realizada a castração dos animais.

A mão-de-obra utilizada na fazenda para o cuidado com o gado é de seis pessoas: um funcionário de maior responsabilidade o capataz e cinco vaqueiros, que realizam todo o manejo na propriedade.

\subsection{Despesas diversas na propriedade rural}

São consideradas como despesas diversas aquelas que não alocam nos grupos acima, alguns exemplos a citar: os brincos de identificação dos animais (rastreabilidade), combustível das máquinas, contribuição sindical rural, encargos financeiros, material de escritório, energia elétrica, fretes e carretos dos animais, horas das máquinas, lubrificantes, materiais de limpeza, reparo e manutenção de máquinas benfeitorias e veículos, e taxas diversas.

\subsection{Depreciação das máquinas equipamentos e implementos e benfeitorias}

Os bens através do seu uso e desgaste físico vão se tornando inúteis e obsoletos, e por isso se faz necessário a sua substituição. A depreciação é utilizada para estimar a vida útil do bem e assim a perda de seu valor, podendo sofrer depreciação todo bem que tenha vida útil superior a um ciclo produtivo, utilizando a depreciação somente para bens que tenham a sua vida útil limitada. Na fazenda a depreciação do trator e da 
Custo do gado bovino rastreado da fazenda cachoeira e outras em Tangará da Serra: uso do custeio variável

Ederson Junio Pelissari, Laércio Juarez Melz, Cleiton Franco, Priscila Meliane Leite dos Anjos

carretinha que é utilizada para salgar os cochos de sal, é realizada linearmente, ou seja, com parcelas de igual valor a cada mês.

\subsection{Características das propriedades entrevistadas.}

$\mathrm{Na}$ tabela 5 através das respostas dos entrevistados buscou-se caracterizar as propriedades e traçar um perfil em relação às respostas e quantidade de animais por propriedade, buscando saber qual é tempo de rastreabilidade, e quantos meses os animais permanecem na propriedade ganhando peso esperando para o abate, e também qual é o sistema de produção utilizado em cada propriedade.

Tabela 6. Quais as características das propriedades entrevistadas, quantos anos de rastreabilidade, qual o tempo de permanência dos animais até o abate e o sistema de produção utilizado na fazenda.

\begin{tabular}{|c|c|c|c|c|c|}
\hline \multirow[b]{2}{*}{ Questão } & \multirow[b]{2}{*}{ Resposta } & \multicolumn{4}{|c|}{ Quantidade de Animais } \\
\hline & & 501 a 1000 & 1001 a 5000 & acima de 5001 & Total Geral \\
\hline Anos de atividade rastreado & 6 a 10 anos & 2 & 7 & 3 & 12 \\
\hline \multirow{3}{*}{$\begin{array}{l}\text { Quantidade de meses dos animais } \\
\text { na propriedade }\end{array}$} & até 24 meses & & & 1 & 1 \\
\hline & 25 a 36 meses & 2 & 9 & 2 & 13 \\
\hline & mais de 36 meses & & 3 & & 3 \\
\hline \multirow{3}{*}{ Sistema de manejo utilizado } & Sistema semi-extensivo & 2 & 9 & 2 & 13 \\
\hline & Sistema extensivo & & 3 & 1 & 4 \\
\hline & Total Geral & 2 & 12 & 3 & 17 \\
\hline
\end{tabular}

Foram perguntados, quantos anos a propriedade tem a atividade pecuária rastreada, onde do total de respostas a mais expressiva foram, 12 entrevistados que responderam de 6 a 10 anos de atividade, destes mesmos a quantidade maior está na faixa de 1001 a 5000 animais em suas propriedades. Foram perguntadas também sobre o tempo de permanência dos animais na propriedade até o abate, as respostas mais expressivas foram, 13 entrevistados que responderam que os animais ficam na propriedade de 24 a 36 meses, onde 9 dos entrevistados fazem parte da faixa de 1001 a 5000 animais em suas propriedades. Foram perguntados também sobre qual o sistema de produção utilizado na propriedade rural, dos entrevistados 13 responderam que o mais utilizado é o sistema semi-extensivo, onde 9 propriedades fazem parte da faixa de 1001 a 5000 animais.

\subsection{Processo de produção do gado rastreado}

Na tabela 6 através das respostas dos entrevistados procurou-se buscar quais são as etapas dos animais rastreados e quais são as principais diferenças em relação ao gado não rastreado e procurou-se saber qual é o custo mensal por animal na propriedade. 
Custo do gado bovino rastreado da fazenda cachoeira e outras em Tangará da Serra: uso do custeio variável

Ederson Junio Pelissari, Laércio Juarez Melz, Cleiton Franco, Priscila Meliane Leite dos Anjos

Tabela 7. Quais são as etapas que os animais passam na propriedade e quais são as diferenças entre os animais rastreados e não rastreados na propriedade, e qual é o custo mensal por animal.

\begin{tabular}{|c|c|c|c|c|c|}
\hline & & \multicolumn{4}{|c|}{ Quantidade de Animais } \\
\hline & & $\begin{array}{l}501 \text { a } \\
1000\end{array}$ & $\begin{array}{c}1001 \text { a } \\
5000\end{array}$ & $\begin{array}{c}\text { acima de } \\
5001\end{array}$ & $\begin{array}{l}\text { Total } \\
\text { Geral }\end{array}$ \\
\hline \multirow{3}{*}{$\begin{array}{l}\text { Etapas do gado } \\
\text { rastreado }\end{array}$} & $\begin{array}{l}\text { nascimento ou compra / sanidade do } \\
\text { período / abate }\end{array}$ & 2 & 11 & 2 & 15 \\
\hline & segue as normas da IN 17 & & 1 & 1 & 2 \\
\hline & Total Geral & 2 & 12 & 3 & 17 \\
\hline \multirow{3}{*}{$\begin{array}{c}\text { Diferenças para os } \\
\text { animais não } \\
\text { rastreados }\end{array}$} & $\begin{array}{l}\text { além de menor controle, menor custo na } \\
\text { propriedade }\end{array}$ & 2 & 11 & 2 & 15 \\
\hline & rastreabilidade não necessária & & 1 & 1 & 2 \\
\hline & Total Geral & 2 & 12 & 3 & 17 \\
\hline \multirow{9}{*}{$\begin{array}{l}\text { Qual o custo por } \\
\text { cabeça mensal ? }\end{array}$} & 18,00 em média por animal & & 1 & & 1 \\
\hline & 20,00 em média por animal & 2 & 2 & 1 & 5 \\
\hline & 21,00 em média por animal & & 1 & 1 & 2 \\
\hline & 22,00 em média por animal & & 2 & & 2 \\
\hline & $23,00 \mathrm{em}$ média por animal & & 2 & & 2 \\
\hline & 24,00 em média por animal & & 1 & 1 & 1 \\
\hline & 26,00 em média por animal & & 1 & & 1 \\
\hline & não tem ainda & & 2 & & 2 \\
\hline & Total Geral & 2 & 12 & 3 & 17 \\
\hline
\end{tabular}

Foram perguntados aos entrevistados quais são as principais etapas a serem seguidas para se manter o gado rastreado e habilitado para a exportação UE, onde do total de respostas a mais significativa foi, 15 entrevistados responderam que compram ou nascem os animais na propriedade, rastreiam, fazem toda a sanidade e manejo do período e depois estão prontos para o abate, pertencendo essas propriedades a faixa de 1001 a 5000 animais, nesta mesma pergunta 2 produtores responderam que seguem todas as normas e instruções na IN 17 que determina todas as exigências tanto da propriedade ou dos animais. Foram perguntados também quais são as principais diferenças para animais não rastreados, ou seja, qual o diferencial no dia-dia da propriedade, 15 dos entrevistados disse ter um menor controle e não se preocupar com o controle dos brincos e papéis necessários para as vistorias, tanto da parte da certificadora responsável, quanto das vistorias do Ministério da Agricultura Pecuária e Abastecimento (MAPA), devido a rigorosidade e exigências impostas pela IN 17, onde 11 propriedade estão na faixa de 1001 a 5000 animais.

Já quando foram questionados sobre qual o custo mensal por animal, as respostam foram diversificadas, desde a não saber qual é o custo mensal, e também de $\mathrm{R} \$ 18,00$ até $\mathrm{R} \$ 26,00$ reais por cabeça mensal. 
Custo do gado bovino rastreado da fazenda cachoeira e outras em Tangará da Serra: uso do custeio variável

Ederson Junio Pelissari, Laércio Juarez Melz, Cleiton Franco, Priscila Meliane Leite dos Anjos

\subsection{Vantagens e desvantagens da rastreabilidade bovina}

No quadro 7 através das respostas dos entrevistados procurou-se saber quais são as principais vantagens e quais são as principais desvantagens de se optar pelo rastreamento dos animais para exportação UE.

Quadro 7. Vantagens e desvantagens do uso da rastreabilidade em bovinos segundo as propriedades entrevistadas.

\begin{tabular}{|l|l}
\hline \multicolumn{1}{|c|}{ Vantagens } & \multicolumn{1}{c}{ Desvantagens } \\
- Bônus no preço de venda & - Acompanhamento em vistorias \\
& - Controle rigoroso dos animais \\
- Competitividade de produto na hora do abate & - Burocracia em documentos e papéis \\
- Maior controle dos animais & - Controle da perda de brincos \\
- Ter opção de escolher o melhor preço na hora da & - Manejo mais rigoroso \\
venda para um frigorífico & - Tensão em vistorias - MAPA \\
& - Aumento do custo por animal pelo uso e \\
& manutenção da rastreabilidade.
\end{tabular}

Foram perguntados a todos os entrevistados quais eram as suas maiores vantagens e desvantagens em relação à rastreabilidade e a permanência no sistema, todos apontaram que no processo de rastreabilidade existem vantagens e desvantagens, porém permanecer no sistema é para poucos, pois um erro em qualquer documento seja ele uma simples assinatura constatada em uma vistoria oficial pelo MAPA. Já descredencia o estabelecimento rural da lista trace, todos apontaram grandes vantagens e desvantagens, mais todos ao optarem por essa modalidade concordam e sabem das exigências e riscos em permanecer no sistema de rastreabilidade, e são unânimes em afirmar que é compensador submeter a propriedade a tais exigências.

Tabela 8. Qual é o valor médio da arroba para venda de bovinos em frigorífico exportador.

\begin{tabular}{lcccc}
\hline & \multicolumn{3}{c}{ Quantidade de Animais } \\
\cline { 2 - 5 } $\begin{array}{l}\text { Qual o valor pago maior por arroba pelo gado } \\
\text { rastreado }\end{array}$ & $\mathbf{5 0 1}$ a & $\mathbf{1 0 0 1}$ a & acima de & Total \\
Geral
\end{tabular}

O bônus pago aos produtores pela arroba de carne rastreada é de média de R\$ 3,00 reais, podendo variar em épocas do ano, onde a procura se eleva devido a contratos firmados pelos frigoríficos exportadores aos países compradores, obrigando assim a pagar um bônus maior em forma de incentivo para fechar seus contratos. Todos os produtores são unânimes em afirmar que esse bônus pago a eles, incentiva a atividade e superam todas as desvantagens e fazendo assim a atividade pecuária rastreada ser vantajosa quando usada nos animais. 
Custo do gado bovino rastreado da fazenda cachoeira e outras em Tangará da Serra: uso do custeio variável

Ederson Junio Pelissari, Laércio Juarez Melz, Cleiton Franco, Priscila Meliane Leite dos Anjos

\subsection{Valor médio pago pela certificação e inclusão dos animais rastreados nas propriedades rurais entrevistadas.}

Na tabela 8 através das respostas dos entrevistados pode-se fazer uma média do valor pago a cada conjunto de elemento de identificação, e também sobre o valor da certificação das propriedades.

Tabela 9. Qual é o valor médio do custo de certificação dos animais e da propriedade a cada 6 meses.

\begin{tabular}{ccccc}
\hline & \multicolumn{4}{c}{ Quantidade de Animais } \\
\cline { 4 - 5 } Quais são os custos nas etapas de produção (média). & $\mathbf{5 0 1}$ a 1000 & $\mathbf{1 0 0 1}$ a 5000 & acima de 5001 & Total Geral \\
\hline $\begin{array}{c}\text { brincos; } \mathbf{1 , 4 6} \text { (média) } \\
\text { inclusão; 1,94 (média) }\end{array}$ & 12 & 2 & 3 & 17 \\
$\begin{array}{c}\text { certificação1.300 cada 6 meses (média) } \\
\text { Total Geral }\end{array}$ & $\mathbf{1 2}$ & $\mathbf{2}$ & $\mathbf{3}$ & $\mathbf{1 7}$ \\
\hline
\end{tabular}

Através da resposta dos entrevistados podem-se identificar quais são os valores pagos pela aquisição dos conjuntos de elementos identificadores, contendo brinco, botton e machinho, que está em média de R \$1,46. Já a inclusão dos animais no sistema de rastreabilidade junto com certificado, está em média de $\mathrm{R} \$ 1,94$. Já a vistoria de renovação do certificado ERAS da propriedade, onde são analisados todos os documentos dos animais desde assinaturas e preenchimentos de documentos, está em média de $\mathrm{R} \$ 1.300,00$ por vistoria, sendo realizada nova vistoria a cada semestre.

\section{CONCLUSÃO}

O Problema da pesquisa proposto foi: $\mathrm{O}$ custo de manter a rastreabilidade de bovinos de corte é vantajoso para as empresas rurais de Tangará da Serra, a partir da aplicação do custeio variável para identificar os custos?

Concluiu-se que o custo de manter a rastreabilidade de bovinos de corte é vantajoso para as empresas rurais de Tangará da Serra, a partir da aplicação do custeio variável para identificar os custos. Para cada animal rastreado vendido com, no mínimo, 15 arrobas, o produtor recebe $\mathrm{R} \$ 45,00$ de bônus. Os custos de manter a rastreabilidade totalizam R $\$ 5,38$ por cabeça no período de 27 meses. O lucro gerado para engordar o gado rastreado seria, portanto, de $\mathrm{R} \$ 39,62$ por animal ou $\mathrm{R} \$ 2,64$ por arroba.

Esta pesquisa tem como limitação a realidade dos cálculos de Tangará da Serra na fazenda cachoeira onde foram levantados dados através aplicação de questionário e 
dados fornecidos pelo proprietário. Fica como sugestão a aplicação da pesquisa em outras regiões de Mato Grosso e até mesmo em outros estados do Brasil.

\section{REFERÊNCIAS}

ABIEC. Associação Brasileira de Indústrias Exportadoras de Carnes. Setor de carnes terá produção e consumo maiores em 2011. Disponível em: <http://www.abiec.com.br/news_view.asp?id=\%7B3C8447AB-0F7C-4E30-B767C15CC02B4CCE\%7D $\geq$. Acesso em: 23 out. 2010.

ACRIMAT-Associação dos criadores de Mato Grosso, 2011. Disponivel em: <http://www.acrimat.com.br/newsletter>. Acesso em: 5 maio 2011.

CNA-Confederação da Agricultura e Pecuária do Brasil. Relatório de atividade 2010/2011. Disponivel em: <http://www.cna.org.br>. Acesso em: 5 maio 2011.

CREPALDI, S. A. Contabilidade gerencial: teoria e prática. 3. ed. São Paulo: Atlas, 2005.

FATEC S/A. Rastreabilidade, 2011. Disponivel em: <http://www.fatec.com.br/rastreabilidade.html>. Acesso em: 2 maio 2011.

GUANZIROLI, C. E.; BUAINAIN, A. M.; SOUZA FILHO, H. M. Metodologia para estudo das relações de mercado em sistemas agroindustriais. Brasilia: IICA, 2008.

IBGE-Instituto Brasileiro de Geografia e Estatística. Efetivo dos rebanhos por tipo de rebanho, 2011. Disponivel em: $<\mathrm{http}: / / \mathrm{www}$. sidra.ibge.gov.br/bda/tabela/listabl.asp?z=t\&o=24\&i=P\&c=73>. Acesso em: 11 abril 2011.

INDEA-Instituto de defesa agropecuário. Entrevista pessoal - Lauri Martins em 25 maio 2011.

IN 17 - Instrução normativa dezessete 2011. Disponível em: <http://www.sbcert.com.br/?lk=Downloads>. Acesso em 18 de abril de 2011.

MAPA. Ministério da Agricultura, Pecuária e Abastecimento. Instrução Normativa no 017, de 13 de julho de 2006. Disponível em: <http://www.agricultura.rs.gov.br/uploads/12754996131182539130IN_17_2006.pdf>. Acesso em: 18 abr. 2011.

MDIC-Ministério do Desenvolvimento, Indústria e Comércio Exterior. Exportação brasileira, 2011. Disponível em: <http://aliceweb.desenvolvimento.gov.br/>. Acesso em: 25 abril 2011.

MARION, J. C. Contabilidade da pecuária. 8. ed. São Paulo: Atlas, 2007a.

Contabilidade rural. 7. ed. São Paulo: Atlas, $2007 \mathrm{~b}$.

MARTINS, E. Contabilidade de custos. 9.ed. São Paulo: Atlas, 2003.

MEGLIORINI, E. Custos: análise e gestão.2.ed. São Paulo: Pearson Prentice Hall, 2007.

PADOVEZE, C. L. Contabilidade gerencial: um enfoque em sistema de informação contábil. 4. ed. São Paulo: Atlas, 2003. 
PEREZ JUNIOR, J. H.; OLIVEIRA, L. M. D.; COSTA, R. G. Gestão estratégica de custos. 3. ed. São Paulo: Atlas, 2003.

RIBEIRO, M. A.; TORRES, A. L.; ROCHA, M. A. Manual para elaboração e apresentação de monografias. Tangará da Serra: UNEMAT, 2006.

SCRAMIN, F. C. L.; BATALHA, M. O. Gestão de custos agroindustriais. In: BATALHA, M. O. Gestão agroindustrial. 3. ed. São Paulo: Atlas, v. I, 2007. Cap. 7, p. 431-502.

SYSRASTRO-Sistema de rastreabilidade bovina e bufalina, 2011. Disponivel em: <http://www.sysrastro.com.br/sysrastro/rastreabilidade.php>. Acesso em: 19 abril 2011. 